\title{
Factors associated with women's intention to request caesarean delivery in Dar es Salaam, Tanzania
}

\author{
C G Misaeli, ${ }^{1}$ MD, MMed; B A Kamala, ${ }^{2,3}$ MD, MPH; A H Mgaya ${ }^{2,4}$ MD, MMed, PhD; H L Kidanto, ${ }^{2,4}$ MD, MMed, PhD
}

${ }^{1}$ Department of Obstetrics and Gynaecology, Muhimbili University of Health and Allied Science, Dar es Salaam, Tanzania

${ }^{2}$ Department of Obstetrics and Gynaecology, Muhimbili National Hospital, Dar es Salaam, Tanzania

${ }^{3}$ Department of Health Science, University of Stavanger, Stavanger, Norway

${ }^{4}$ Department of Women's and Children's Health/International Maternal and Child Health, Uppsala University, Sweden

Corresponding author: B A Kamala (kamala8086@gmail.com)

\begin{abstract}
Background. In the past decade, the rate of caesarean section (CS) has increased dramatically in many parts of the world. At Muhimbili National Hospital (MNH) there has been a dramatic rise in the caesarean section rate over the past decade.

Objective. To determine the incidence of maternal request for CS and factors associated with intention to request caesarean section at the MNH antenatal clinic.

Methods. We conducted a cross-sectional study from August to October 2014. A structured questionnaire gathered participants' background and obstetric information, perceptions and opinions regarding a request for caesarean section, and the respective reasons for the request. Confidence intervals were calculated and a $p$-value $<0.05$ was considered significant.

Results. The incidence of CS on maternal request was about $6 \%$. The intention to request for CS in the index pregnancy was $8 \%$. Higher-level education and formal-sector employment had higher odds for requesting CS ( $p=0.01$ and $p=0.05$, respectively). Half of the participants agreed that maternal request for CS should be allowed; more private patients agreed that it could affect the doctor-patient relationship ( $p=0.02)$; more private patients agreed that request for CS was due to fear of losing a child $(p=0.03)$. Previous history of CS was an independent predictor of maternal request for caesarean section (OR 1.7; 95\% CI 1.7 - 15.4) and (OR 5.8; 95\% CI 1.6 - 20.1), respectively.

Conclusion. Maternal requests for CS exist at the national referral hospital in Tanzania. This was associated with factors other than women's preferences, including perceived fear of child loss and events associated with previous CS.
\end{abstract}

S Afr J Obstet Gynaecol 2017;23(2):56-62. DOI: 10.7196/SAJOG.2017.v23i2.1158

Caesarean section (CS) on maternal request implies patient choice for caesarean delivery, or CS on demand without maternal or fetal indications. ${ }^{[1]}$ The concept of CS on maternal request is not well-defined as a clinical entity despite progress in establishing policy guidance for the procedure for CS on maternal request. ${ }^{[2]}$ Healthcare providers may be uncertain on how to respond to maternal request for CS. In Tanzania, the rates of maternal requests for CS have not been published. ${ }^{[3]}$ In 2014, the birth registry at the national referral hospital, Muhimbili National Hospital (MNH), recorded the highest rate of CS, at $51 \%$, compared with other public hospitals. The high rate of $\mathrm{CS}$ at $\mathrm{MNH}$ was associated with low-risk Robson groups, doubtful CS indications, and increased likelihood of performing CS on request among private patients performed at that hospital compared with public patients. ${ }^{[4,5]}$

According to the Tanzanian Ministry of Health guidelines, CSs are commonly performed for saving the lives of the mothers and newborns. A study at $\mathrm{MNH}$ showed that the total risk of 'near-miss' events associated with CS procedures was $3-7$ per 1000 operations. ${ }^{[6]}$ The risk of CS has been closely associated with unsafe anaesthesia, poor preoperative preparations and delayed interventions due to limited resources. ${ }^{[7]}$ In some settings, limited access to CS has been shown to contribute to severe maternal morbidity, such as postpartum haemorrhage, uterine rupture, puerperal sepsis, genital fistula and maternal death. ${ }^{[8-12]}$ Limited access to CS also imposes a risk of intrapartum asphyxia with subsequent neonatal neurological damage, and perinatal death. ${ }^{[13]}$ Some documented literature reports that patients' autonomy in healthcare includes maternal request for CS, even in the presence of the considerable risk associated with CS and inequity in maternal and newborn healthcare. ${ }^{[14,15]}$ Women's perceptions and their involvement in decision-making regarding CS have been used to draw conclusions relating to women's requests for elective CS without medical grounds. ${ }^{[16]}$ Most women at $\mathrm{MNH}$ receive counselling around the decision to perform CS during admission for labour or when abnormal labour is detected. ${ }^{[17]}$ However, the antenatal care (ANC) clinic provides a better environment with reduced anxiety for making an informed choice. ${ }^{[18]}$

The strategies necessary for reducing maternal and perinatal mortality include adequate antenatal care and appropriate caesarean intervention as part of Comprehensive Emergency Obstetric Care (CEoC). ${ }^{[19,20]}$ At $\mathrm{MNH}$, there are no clear guidelines relating to indications for CS. This has led to subjective indications for CS, including prior recurrent fetal loss, history of infertility and in vitro fertilisation, meconium-stained liquor, and non-assuring fetal heart traces. ${ }^{[17]}$ Also, fear and blame among care providers in case of poor outcome, poorly conducted perinatal audits, maternal perceived fear of birth trauma, and loss of the baby during childbirth are possible reasons for performing unnecessary CS; this may include maternal requests for CS. ${ }^{[21]}$ Interventions to reduce CS rates include fetal monitoring using fetal doppler, training on partography, correct 
audit meetings, engaging mothers in the decision-making process of mode of delivery during antenatal care. Healthcare providers' unawareness of women's opinions of CS on maternal request hinders efforts to reduce unnecessary CS. This study aimed to determine the women's perceptions and intentions for CS on maternal request and the factors associated with that intent.

\section{Methods \\ Study design and setting}

This cross-sectional study was conducted at $\mathrm{MNH}$ antenatal care clinic from August to October 2014. MNH is the largest referral hospital in Tanzania, located in the city of Dar es Salaam. Patients who attend ANC at MNH include referrals cases from public health facilities and patients who come directly from private facilities or from home as private patients under intramural private practice management (IPPM).

\section{Sample size and sampling technique}

The sample size was calculated using OpenEpi version 3 (EpiData Association, Denmark), a software program for population surveys, with the assumption that the anticipated proportion for the desired outcome was $50 \%$, with a precision of $5 \%$, power of $80 \%$, and a design effect of 1 . The minimum required sample size was 384 cases. After the daily health education session, the investigator and research nurse informed all antenatal clinic attendees about the study. On a daily basis, ANC cards of all women who attended the clinic were collected and listed in order to create a sampling frame that was used to assess the eligibility of the study participants. Every fifth card was selected during the day's clinic registration process and the card-holder was identified. Women with communication difficulties were excluded. Also, women with either two previous scars or one previous scar with a percieved recurrent indication for CS, such as cephalopelvic disproportion, were excluded. Out of 462 eligible participants, 440 agreed to participate in the study, yielding a response rate of $95 \%$.

\section{Data collection and research tools}

Data were collected using a structured questionnaire adapted from previous surveys and comprising four sections. ${ }^{[22,20]}$ The first section contained participants' background information. The second section included fertility history, pregnancy history and mode of deliveries, the associated pregnancy outcome, and feedback on previous pregnancies. The third section contained questions about willingness to request $\mathrm{CS}$ and the fourth section contained 12 questions addressing the women's perceptions of CS on maternal request. The questionnaire was translated from English into Swahili and pretested to ensure accuracy and appropriateness of the questions and responses; an obstetrician reviewed the document. Data were collected by the principal investigator and two trained research assistants.

\section{Data analysis}

SPSS version 19 (IBM Corp., USA) was used to perform data entry and cleaning. Descriptive statistics for sociodemographic, past obstetric history, and previous delivery experiences and perceptions were calculated. Pearson's $\chi^{2}$, Fisher's exact test and $t$-tests were performed to compare the association of predictor variables with history and desire to request CS without medical grounds. Factors that were significant at $p<0.05$ were analysed by logistic regression.

\section{Definition of variables}

CS on maternal request was defined as a caesarean delivery for a singleton pregnancy on maternal request after 37 completed weeks of gestation in the absence of any medical or obstetric indications. 'Perception of CS on request' referred to participants' opinions on cesarean section on maternal request.

\section{Ethical clearance}

The Muhimbili University of Health and Allied Sciences Research Ethics and Publication committee reviewed the study proposal and granted ethical approval. Permission to conduct the study was obtained from the Executive Director of MNH (ref. no. HD/ MUH/T.130/2012). Informed consent was obtained voluntarily from the participants, who were informed about the objectives of the study, and were assured of confidentiality and that their names would not be used for the purpose of identification.

\section{Results}

Of the 440 participants who were interviewed, more than half (57\%, $n=250)$ were private patients, as shown in Table 1 . Both public and private patients had a mean (SD) age of nearly 30 (5) years. There were more public patients in the category of those participants aged less than 25 years compared with other categories $(p=0.07$ ). Most of the patients $(90 \%)$ had been married at least once in their lifetime and there was no significant difference in marital status between public and private patients. Private patients were more educated compared with public patients ( $61 \%$ v. $25 \%$ for tertiary education; $p=0.01)$. Similarly, there was a lower proportion of public patients who were employed in the formal sector compared with the private patients $(63.5 \%$ v. $28.3 \%$; $p<0.001)$.

Table 1. Sociodemographic characteristics of private and public category of pregnant women in the study cohort

\begin{tabular}{|c|c|c|c|c|}
\hline Characteristics & $\begin{array}{l}\text { Total } \\
(N=440), \\
n(\%)\end{array}$ & $\begin{array}{l}\text { Private } \\
(n=249), \\
n(\%)\end{array}$ & $\begin{array}{l}\text { Public } \\
(n=191), \\
n(\%)\end{array}$ & $p$-value \\
\hline \multicolumn{5}{|l|}{ Age (years) } \\
\hline$\leq 25$ & $84(19.1)$ & $41(16.5)$ & $43(22.5)$ & \\
\hline $26-30$ & $172(39.1)$ & $98(39.4)$ & $74(38.7)$ & \\
\hline $31-34$ & $94(21.4)$ & $63(25.3)$ & $31(16.2)$ & \\
\hline$\geq 35$ & $90(20.5)$ & 47 (18.9) & $43(22.5)$ & \\
\hline $\begin{array}{l}\text { Age (years), } \\
\text { mean (SD) }\end{array}$ & $29.8(5.01)$ & $29.9(4.87)$ & $29.7(5.19)$ & 0.07 \\
\hline \multicolumn{5}{|l|}{ Marital status } \\
\hline Single & $45(10.3)$ & $22(8.8)$ & $23(12.0)$ & \\
\hline Ever married & $395(89.7)$ & 227 (91.2) & $168(88.0)$ & 0.27 \\
\hline \multicolumn{5}{|l|}{ Education level } \\
\hline $\begin{array}{l}\text { Primary school } \\
\text { or less }\end{array}$ & 95 (21.6) & $31(12.4)$ & $64(33.5)$ & \\
\hline Secondary school & $144(32.7)$ & $65(26.2)$ & $79(41.4)$ & \\
\hline College/university & $201(45.7)$ & $153(61.4)$ & $48(25.1)$ & 0.01 \\
\hline \multicolumn{5}{|l|}{ Occupation } \\
\hline Employed & $216(49.1)$ & $158(63.5)$ & $58(28.5)$ & \\
\hline Petty trader & $127(28.9)$ & $54(21.7)$ & $73(39.2)$ & \\
\hline Other & $97(22.0)$ & $37(14.8)$ & $60(32.3)$ & 0.01 \\
\hline$S D=$ standard deviation. & & & & \\
\hline
\end{tabular}


When assessing the mode of delivery in the last pregnancy, the rate of previous CS was $42 \%$, of which $14 \%$ were elective and $28 \%$ were emergency CS (Table 2). The rate of previous stillbirths was as high as $15 \%$, and higher among private patients (19\%) compared with their public counterparts (12\%). The proportions of live births, stillbirths and miscarriages were comparable between the private and public groups ( $p=0.35$ ). Twelve percent of the studied group had a history of infertility, and $38 \%$ of the patients were primiparas. The mean (SD) age at first pregnancy was 25 (4.6) years, with private clients being significantly older than their public counterparts $(t(435)=4.58 ; p=0.001)$.

Different background characteristics were analysed for an association with maternal request for CS in the previous pregnancy (Table 3). Patients with secondary school education or higher were more likely to request CS than those with primary education or no formal education $(7.7 \%$ v. $1.4 \% ; p=0.05)$. Similarly, patients who had been employed in the formal sector $(9.2 \%)$ were more likely to request CS than informal traders $(2.1 \%)$ and others $(3.5 \%)(p=0.005)$. Other background characteristics had no significant association with maternal request for CS (all $p \geq 0.17$ ).

The perception of maternal request for CS based on 'fear of losing a child on normal delivery' was more prevalent among private patients compared with their public counterparts $(51 \%$ v. $38 \% ; p=0.03$ ) (Table 4). More private patients also agreed that requesting to deliver by caesarean section could affect the doctorpatient relationship, compared with their public counterparts $(44 \%$

Table 2. Comparison of past obstetric history between private and public pregnant women in the study cohort

\begin{tabular}{|c|c|c|c|c|}
\hline Obstetric history & $\begin{array}{l}\text { Total } \\
(N=440), \\
n(\%)\end{array}$ & $\begin{array}{l}\text { Private } \\
(n=249), \\
n(\%)\end{array}$ & $\begin{array}{l}\text { Public } \\
(n=191), \\
n(\%)\end{array}$ & $p$-value \\
\hline \multicolumn{5}{|l|}{$\begin{array}{l}\text { Mode of delivery of } \\
\text { the last pregnancy }\end{array}$} \\
\hline NVD & $145(57.8)$ & $71(60.7)$ & $74(55.2)$ & \\
\hline Elective CS & 35 (13.9) & $14(12.0)$ & $21(15.7)$ & \\
\hline Emergency CS & $71(28.3)$ & $32(27.3$ & $39(29.1)$ & 0.61 \\
\hline \multicolumn{5}{|l|}{$\begin{array}{l}\text { Outcome of last } \\
\text { pregnancy }^{\dagger}\end{array}$} \\
\hline Live birth & $206(69.8)$ & $91(65.4)$ & $115(73.7)$ & \\
\hline $\begin{array}{l}\text { Macerated still } \\
\text { birth }\end{array}$ & $23(7.8)$ & $13(9.4)$ & $10(6.4)$ & \\
\hline Fresh still birth & $22(7.5)$ & $13(9.4)$ & $9(5.8)$ & \\
\hline Miscarriage & $44(14.9)$ & $22(15.8)$ & $22(14.1)$ & 0.35 \\
\hline \multicolumn{5}{|l|}{ History of infertility } \\
\hline Yes & $54(12.3)$ & $25(13.1)$ & $29(11.6)$ & \\
\hline No & $386(87.7)$ & $166(86.9)$ & $220(88.4)$ & 0.65 \\
\hline \multicolumn{5}{|l|}{ Parity } \\
\hline Nulliparous & $167(38)$ & $102(41.0)$ & $65(34.0)$ & \\
\hline Primiparous & $145(33)$ & $87(34.9)$ & $58(30.4)$ & \\
\hline Multiparous & $128(29)$ & $60(24.1)$ & $68(35.6)$ & 0.14 \\
\hline $\begin{array}{l}\text { Age at first } \\
\text { pregnancy (years), } \\
\text { mean (SD) }\end{array}$ & $25.05(4.6)$ & $25.9(4.4)$ & $23.9(4.6)$ & 0.001 \\
\hline \multicolumn{5}{|c|}{$\begin{array}{l}\mathrm{NVD}=\text { Normal vaginal delivery; } \mathrm{CS}=\text { caesarean section; } \mathrm{SD}=\text { standard deviation. } \\
{ }^{*} \text { Excluded primigravida and miscarriages. } \\
\text { †Excluded miscarriages. }\end{array}$} \\
\hline
\end{tabular}

v. $32 \% ; p=0.02$ ). Other perspectives of women's perceptions were not significantly different between the private and public patients. Intention to request to deliver by CS was reported by approximately $8 \%$ of the respondents. Previous history of CS was the only factor that was a significant predictor of the intention to request CS in the index pregnancy $(p=0.001)$ (Table 5$)$.

Factors that were associated with reproductive history and previous delivery outcomes in the bivariate analysis were entered in the regression model (Table 6). The intention to request for CS was 6-fold more likely among patients who had a previous elective CS delivery than those who had vaginal delivery (adjusted odds ratio (AOR) 5.8; 95\% CI 1.6 - 20.2). Furthermore, patients who had had a previous emergency CS were 5-fold more likely to request CS compared with those who delivered vaginally in their previous pregnancy (AOR 5.1; 95\% CI 1.7 - 15.4). Study participants were less willing to request CS in other public low-referral point health facilities compared with private health facilities. Other factors related to intention to deliver by CS were not statistically significant.

\section{Discussion}

This study revealed that the proportion of women who had a history of requesting CS was $6 \%$ and those intending to request CS was $8 \%$. The main reasons for requesting CS were fear of losing a baby and a history of previous CS. Even though the proportion requesting CS seems small, it is highly likely to increase, based on the trend of increasing numbers of CS birth at MNH. In this hospital, CS births

Table 3. Comparison of maternal characteristics with the history of CS on request among pregnant women in study cohort

\begin{tabular}{|c|c|c|c|}
\hline \multirow[b]{2}{*}{ Characteristic } & \multicolumn{2}{|c|}{$\begin{array}{l}\text { Ever requested to deliver } \\
\text { by CS? }\end{array}$} & \multirow[b]{2}{*}{$p$-value } \\
\hline & Yes, $n(\%)^{*}$ & No, $n(\%)^{*}$ & \\
\hline \multicolumn{4}{|l|}{ Type of clinic } \\
\hline Public & $4(3.2)$ & $122(96.8)$ & \\
\hline Private (IPPM) & $11(7.5)$ & $136(92.5)$ & 0.18 \\
\hline \multicolumn{4}{|l|}{ Education level } \\
\hline Primary or less & $1(1.4)$ & $76(98.6)$ & \\
\hline Secondary and above & $14(7.7)$ & $182(92.3)$ & 0.05 \\
\hline \multicolumn{4}{|l|}{ Age (years) } \\
\hline$<25$ & $2(8.3)$ & $22(91.7)$ & \\
\hline $26-30$ & $6(5.8)$ & $97(94.2)$ & \\
\hline $31-34$ & $6(5.9)$ & $95(94.1)$ & \\
\hline$>35$ & $1(2.2)$ & $44(97.8)$ & 0.71 \\
\hline \multicolumn{4}{|l|}{ Occupation } \\
\hline Employed & $11(9.2)$ & $108(90.8)$ & \\
\hline Informal trader & $2(2.1)$ & $94(97.9)$ & \\
\hline Others & $2(3.4)$ & $56(96.6)$ & 0.05 \\
\hline \multicolumn{4}{|l|}{ Parity } \\
\hline Primiparous & $10(6.9)$ & $135(93.1)$ & \\
\hline Multiparous & $5(3.9)$ & $123(96.1)$ & 0.279 \\
\hline $\begin{array}{l}\text { Age at first pregnancy } \\
\text { (years), mean (SD) }\end{array}$ & $23.7(4.0)$ & $24(4.2)$ & 0.76 \\
\hline $\begin{array}{l}\text { CS = caesarean section; IPPM = i } \\
\text { deviation. } \\
{ }^{*} \text { Unless otherwise specified }\end{array}$ & ural private prac & management; SD & andard \\
\hline
\end{tabular}


Table 4. Comparison of different perceptions of CS on request among pregnant women in study cohort

\begin{tabular}{|c|c|c|c|c|}
\hline Perceptions of CS on request & $\begin{array}{l}\text { Total }(N=440) \\
n(\%)\end{array}$ & $\begin{array}{l}\text { Private }(n=249) \\
n(\%)\end{array}$ & $\begin{array}{l}\text { Public }(n=191) \\
n(\%)\end{array}$ & $p$-value \\
\hline \multicolumn{5}{|l|}{ CS on request should be allowed } \\
\hline Disagree & $202(46.0)$ & $111(44.4)$ & $91(47.9)$ & \\
\hline Not sure & $31(7.0)$ & $19(7.6)$ & $12(6.3)$ & \\
\hline Agree & $207(47.0)$ & $120(48.0)$ & $87(45.8)$ & 0.77 \\
\hline \multicolumn{5}{|c|}{ Doctor has the right to overrule CS on maternal request } \\
\hline Disagree & $90(20.5)$ & $52(20.9)$ & $38(19.9)$ & \\
\hline Not sure & $64(14.5)$ & $29(11.6)$ & $35(18.3)$ & \\
\hline Agree & $286(65.0)$ & $168(67.5)$ & $118(61.8)$ & 0.14 \\
\hline \multicolumn{5}{|c|}{ Women who request delivery by CS had history of infertility } \\
\hline Disagree & $255(58.0)$ & $139(55.8)$ & $116(60.7)$ & \\
\hline Not sure & $130(29.5)$ & $75(30.1)$ & $55(28.8)$ & \\
\hline Agree & $55(12.5)$ & $35(14.1)$ & $20(10.5)$ & 0.44 \\
\hline \multicolumn{5}{|c|}{ Women who request delivery by CS due to previous miscarriage } \\
\hline Disagree & $205(46.6)$ & $111(44.4)$ & $94(49.5)$ & \\
\hline Not sure & $88(20)$ & 49 (19.6) & $39(20.5)$ & \\
\hline Agree & $147(33.4)$ & $90(36.0)$ & $57(30.0)$ & 0.39 \\
\hline \multicolumn{5}{|c|}{ Women who request delivery by CS are $>35$ years old } \\
\hline Disagree & $230(52.3)$ & $123(49.4)$ & $107(56.0)$ & \\
\hline Not sure & $76(17.3)$ & $45(18.1)$ & $31(16.2)$ & \\
\hline Agree & $134(30.5)$ & $81(32.5)$ & $53(27.7)$ & 0.38 \\
\hline \multicolumn{5}{|c|}{ Women who request delivery by CS have psychological problems } \\
\hline Disagree & $182(41.4)$ & $100(40.2)$ & $82(42.9)$ & \\
\hline Not sure & $103(23.4)$ & $53(21.3)$ & $50(26.2)$ & \\
\hline Agree & $155(35.2)$ & $96(38.6)$ & $59(30.9)$ & 0.21 \\
\hline \multicolumn{5}{|c|}{ Women who request delivery by CS are financially well supported } \\
\hline Disagree & $206(46.8)$ & $111(44.6)$ & $95(49.7)$ & \\
\hline Not sure & $55(12.5)$ & $28(11.2)$ & $27(14.1)$ & \\
\hline Agree & $179(40.7)$ & $110(44.2)$ & $69(36.1)$ & 0.21 \\
\hline \multicolumn{5}{|c|}{$\begin{array}{l}\text { Women who request delivery by CS have a fear of losing a child on normal } \\
\text { delivery }\end{array}$} \\
\hline Disagree & $167(38)$ & $84(33.7)$ & $83(43.5)$ & \\
\hline Not sure & $73(16.6)$ & $38(15.3)$ & $35(18.3)$ & \\
\hline Agree & $200(45.5)$ & $127(51.0)$ & $73(38.2)$ & $0.03^{*}$ \\
\hline \multicolumn{5}{|c|}{ Women who request delivery for CS have a fear of labour pain } \\
\hline Disagree & $54(12.3)$ & $25(10.0)$ & $29(15.2)$ & \\
\hline Not sure & $37(8.4)$ & $20(8.0)$ & $17(8.9)$ & \\
\hline Agree & $349(79.3)$ & $204(81.9)$ & $145(75.9)$ & 0.23 \\
\hline \multicolumn{5}{|c|}{ Requesting delivery by CS can affect doctor-patient relationship } \\
\hline Disagree & $167(38)$ & $88(35.2)$ & $79(41.6)$ & \\
\hline Not sure & $100(22.7)$ & $50(20)$ & $50(26.3)$ & \\
\hline Agree & $173(39.3)$ & $112(44.8)$ & $61(32.1)$ & $0.02^{*} 0$ \\
\hline \multicolumn{5}{|c|}{ Women who request delivery by CS have a need to undergo tubal ligation } \\
\hline Disagree & $130(29.5)$ & $78(31.3)$ & $52(27.2)$ & \\
\hline Not sure & $209(47.5)$ & $110(44.2)$ & 99 (51.8) & \\
\hline Agree & $101(23)$ & $61(24.5)$ & $40(20.9)$ & 0.28 \\
\hline \multicolumn{5}{|c|}{$\begin{array}{l}\text { Women who request delivery by CS will have less pelvic flow injury } \\
\text { compared with normal delivery }\end{array}$} \\
\hline Disagree & $124(28.2)$ & $63(25.3)$ & $61(31.9)$ & \\
\hline Not sure & $157(35.7)$ & $96(38.6)$ & $61(31.9)$ & \\
\hline Agree & $159(36.1)$ & $90(36.1)$ & $69(36.1)$ & 0.22 \\
\hline
\end{tabular}


increased from $22 \%$ in 2002 to $51 \%$ in 2014, and therefore there is a need to examine the factors that affect women's decisions to elect for CS, based on their attitudes and experiences.

Fear of losing a child was a predictor for maternal request for CS, as was reported in a study in Sweden in which $28 \%$ of respondents believed that requesting for CS was based on their concerns for the newborn. ${ }^{[23]}$ Having a negative perception of childbirth based on the mother's experience in a prior pregnancy and a history of obstetric complications could be the underlying

Table 5. Factors associated with intention to undergo CS on maternal request ${ }^{*}$

\begin{tabular}{|c|c|c|c|c|}
\hline \multirow[b]{2}{*}{ Factors } & \multicolumn{3}{|c|}{ Intend to request delivery by $\mathrm{CS}$} & \multirow[b]{2}{*}{$p$-value } \\
\hline & $\begin{array}{l}\text { Yes, } \\
n(\%)\end{array}$ & $\begin{array}{l}\text { No, } \\
n(\%)\end{array}$ & $\begin{array}{l}\text { Total, } \\
n(\%)\end{array}$ & \\
\hline \multicolumn{5}{|l|}{$\begin{array}{l}\text { Mode of delivery of } \\
\text { the last pregnancy }\end{array}$} \\
\hline NVD & $4(2.7)$ & $141(97.3)$ & $145(100)$ & \\
\hline Elective CS & $6(17.1)$ & $29(82.9)$ & $35(100)$ & \\
\hline Emergency CS & $11(15.5)$ & $60(84.5)$ & $71(100)$ & $0.001^{\dagger}$ \\
\hline \multicolumn{5}{|l|}{$\begin{array}{l}\text { Outcome of your last } \\
\text { pregnancy }\end{array}$} \\
\hline Live birth & $20(9.7)$ & $186(90.3)$ & $206(100)$ & \\
\hline Macerated birth & $1(4.3)$ & $22(95.7)$ & $23(100)$ & \\
\hline Stillbirth & $1(4.5)$ & $21(95.5)$ & $22(100)$ & \\
\hline Miscarriage & $3(6.8)$ & $41(93.2)$ & $44(100)$ & 0.687 \\
\hline \multicolumn{5}{|l|}{$\begin{array}{l}\text { Type of antenatal } \\
\text { care clinic }\end{array}$} \\
\hline Public & $14(7.3)$ & $177(92.7)$ & $191(100)$ & \\
\hline IPPM (private) & $20(8.0)$ & $229(92.0)$ & $249(100)$ & 0.798 \\
\hline \multicolumn{5}{|l|}{ Education level } \\
\hline $\begin{array}{l}\text { Primary school } \\
\text { or less }\end{array}$ & $7(7.4)$ & $88(92.6)$ & $95(100)$ & \\
\hline Secondary school & $11(7.6)$ & $133(92.4)$ & $144(100)$ & \\
\hline College/university & $16(8.0)$ & $185(92.0)$ & $201(100)$ & 0.99 \\
\hline \multicolumn{5}{|l|}{ Age (years) } \\
\hline$<21$ & $6(7.1)$ & $78(92.2)$ & $84(100)$ & \\
\hline $26-30$ & $10(5.8)$ & $162(94.2)$ & $172(100)$ & \\
\hline $31-34$ & $13(10.0)$ & $117(90.0)$ & $130(100)$ & \\
\hline$>35$ & $5(9.3)$ & $49(90.7)$ & $54(100)$ & 0.79 \\
\hline \multicolumn{5}{|l|}{ Occupation } \\
\hline Employed & $19(8.8)$ & $197(91.2)$ & $216(100)$ & \\
\hline Informal trader & $9(7.1)$ & $118(92.9)$ & $127(100)$ & \\
\hline Other & $6(6.2)$ & $91(93.8)$ & $97(100)$ & 0.25 \\
\hline \multicolumn{5}{|l|}{ Ever delivered by CS } \\
\hline Yes & $19(16.7)$ & $95(83.3)$ & $114(100)$ & \\
\hline No & $4(2.5)$ & $155(97.5)$ & $159(100)$ & $0.001^{\dagger}$ \\
\hline \multicolumn{5}{|l|}{$\begin{array}{l}\text { Have you ever had an } \\
\text { infertility problem }\end{array}$} \\
\hline Yes & $4(20.0)$ & $16(80.0)$ & $20(100)$ & \\
\hline No & $13(14.6)$ & $76(85.4)$ & 89 (100) & 0.55 \\
\hline \multicolumn{5}{|c|}{$\begin{array}{l}\mathrm{CS}=\text { caesarean section } ; \mathrm{NVD}=\text { normal vaginal delivery; } \mathrm{IPPM}=\text { intramural private practice } \\
\text { management. }\end{array}$} \\
\hline \multicolumn{5}{|c|}{ * Some numbers do not add up to the total due to missing values in some variables. } \\
\hline
\end{tabular}

reason for expressing concern for the new baby and, subsequently, the maternal request for CS. ${ }^{[24]}$ Prior local evidence has highlighted that mothers' perceptions of maternal complications and risk, the chance of delivering a healthy baby following previous poor outcome, or an external influence such as seeking experience and advice from peers, are all contributing factors for CS on request. ${ }^{[17]}$ At MNH and other health facilities in Tanzania, understaffing and limited health resources have led to the provision of substandard care; thus, upgrading $\mathrm{CEoC}$ could not only prevent adverse delivery outcomes, but might also contribute to reducing the number of unnecessary CSs based on maternal request.

As shown in this study, previous history of CS was a significant factor associated with requesting CS, and previous emergency CS had a higher likelihood of maternal request for CS compared to previous elective CS. Similar findings have been reported in Canada, Sweden and Nigeria. ${ }^{[20,25,26]}$ Furthermore, evidence has shown that fear of childbirth associated with obstetric complications is usually related to emergency rather than elective CS. Parturients and their newborns in health-resource-limited settings such as in Tanzania have a high risk of severe morbidity during birth due to abnomal labour, which could lead to avoidance of vaginal delivery as a result of a negative perception of childbirth. ${ }^{[17]}$

The findings regarding the influence of advanced maternal age, psychological problems and previous pregnancy loss to intention to request CS were contrary to the findings of other studies. ${ }^{[27]}$ Cultural differences could explain these differences. The participants' unwillingness to request CS in another public referral point at a lower referral level, such as a regional hospital, compared with private health facility could imply women's lack of trust/confidence and the provision of a relatively lower quality of service in these facilities compared with MNH. ${ }^{[6]}$ This finding is supported by Okonkwo et al. ${ }^{[20]}$ who reported that the rate of maternal request for CS was higher in a tertiary hospital compared with secondary and primary health centres. Furthermore, almost half of the participants were of the opinion that CS on request should be allowed and that doctors had the right to overrule maternal request for CS. Nonetheless, participants felt that requesting CS might affect the doctor-patient relationship, which aligns with the findings of a previous qualitative study at $\mathrm{MNH}$ that highlighted maternal anxiety and poor client counselling during childbirth and thus found room for improvement. ${ }^{[17]}$

Evidence relating to the potential benefits of elective CS compared with vaginal delivery has been inconsistent. While some literature supports the notion that elective CS is associated with a decreased risk of urinary incontinence, pelvic organ prolapse, anal sphincter damage, fecal incontinence and flexible timing for the mother, ${ }^{[1,28]}$ others advocate vaginal delivery, considering the risk of adverse outcomes of CS, including haemorrhage, admission to the ICU, blood transfusion and hysterectomy, especially in low-resource settings. ${ }^{[29,30]}$ As with any major surgical procedure, there are risks associated with CS, including complications of anaesthesia, excessive blood loss, breathing problems, infection, urinary tract injury, and injury to the baby. ${ }^{[6,7]}$ In addition, recovery time and hospital stay following caesarean delivery are longer than following vaginal delivery and therefore CS is associated with increased cost of care for the individual, the family and the health system. Therefore, adequate information should be made available to the clients when considering delivery by CS when vaginal delivery is also possible.

This study was conducted at the largest tertiary hospital in Tanzania, which has a rapidly increasing CS rate that represents 
RESEARCH

Table 6. Logistic regression on factors associated with intention of maternal request for CS

\begin{tabular}{|c|c|c|c|c|c|}
\hline Factor & COR & $95 \% \mathrm{CI}$ & AOR & $95 \% \mathrm{CI}$ & $p$-value \\
\hline \multicolumn{6}{|c|}{ Mode of delivery of last pregnancy } \\
\hline NVD & 1 & & 1 & & \\
\hline Elective CS & 6.7 & $1.4-9.3$ & 5.8 & $1.6-20.2$ & 0.006 \\
\hline Emergency CS & 8.1 & $2.6-10.1$ & 5.1 & $1.7-15.4$ & 0.004 \\
\hline \multicolumn{6}{|c|}{ Outcome of last pregnancy } \\
\hline Live birth & 1 & & 1 & & \\
\hline Stillbirth & 0.38 & $0.43-3.2$ & 0.5 & $0.12-1.4$ & 0.83 \\
\hline Miscarriage & 0.11 & $0.14-1.2$ & 0.24 & $0.21-3.1$ & 0.37 \\
\hline \multicolumn{6}{|c|}{ Have you ever had an infertility problem } \\
\hline No & 1 & & 1 & & \\
\hline Yes & 1.25 & $0.35-4.4$ & 1.25 & $0.47-3.39$ & 0.65 \\
\hline
\end{tabular}

a real problem in Tanzanian referral health facilities. The environment within a referral centre could also be the reason for the increase in the number of CS associated with lowrisk pregnancy. ${ }^{[4]}$ The seemingly rare complications of CS, including subsequent placenta praevia with placenta acreta, and endometriosis should be addressed as possible adverse effects of CS during counselling. The reported numbers of maternal request for CS in this study might be biased by the fact that this study was conducted in the largest tertiary urban health facility, which received referred complicated pregnancies as well as private patients with low-risk pregnancies. Furthermore, the national CS rate of $6 \%$ in Tanzania is still below the $10 \%$ that was deemed acceptable based on WHO literature. However, CS rates should not be demand-driven but based on optimal indications. CS without maternal or fetal indications unnecessarily depletes the scarce resources available in a low-income country like Tanzania.

\section{Conclusion}

Maternal requests for CS do exist at the highest national referral hospital in Tanzania. The maternal requests for CS were associated with factors other than women's preferences, including perceived fear of child loss following vaginal delivery and events associated with previous CS. In the absence of maternal or fetal indications for CS, a plan for vaginal delivery is a safe and appropriate option and should be recommended. Care providers have the responsibility of alleviating women's perceived fear of childbirth by providing adequate counselling on their decision of mode of delivery to assist women in making an informed choice. Furthermore, good-quality intrapartum care encourages women to attempt vaginal birth. A deeper understanding of women and health care providers' perceptions and attitudes towards maternal requests for CS through a qualitative approach is also recommended.

Acknowledgements. We acknowledge the voluntary participation of women attending ANC clinic at MNH. We also appreciate the contribution of academic staff in the Department of Obstetrics and Gynaecology of MUHAS, and all physicians and nurses in the Department of Obstetrics and Gynaecology of $\mathrm{MNH}$, who played an invaluable role in the success of this work.

Author contributions. CM designed the study, carried out the collection and analyses of data, and drafted the first version of the manuscript. BK participated in data analysis, interpretation of data and development of the manuscript. AM participated in the interpretation of data, and drafted the first version and final manuscript. HK contributed to the design of the study, data analysis, interpretation of the results and participated in the development of the first and final version of the manuscript. All authors read and approved the final manuscript.

Funding. None.

Conflicts of interest. None.

1. Viswanathan M, Visco AG, Hartmann K, et al. Cesarean delivery on maternal request. Evid Rep Technol Assess 2006;(133):1-138.

2. American College of Obstetricians and Gynecologists. ACOG committee opinion no. 559: Cesarean delivery on maternal request. Obstet Gynecol 2013;121(4):904-907. https://doi.org/10.1097/01. AOG.0000428647.67925.d3

3. National Bureau of Statistics (NBS), ICF Macro. Tanzania Demographic and Health Survey 2010. Dar es Salaam, Tanzania and Calverton, MA: NBS and ICF Macro, 2011.

4. Litorp H, Kidanto HL, Nyström L, Darj E, Essén B. Increasing caesarean section rates among lowrisk groups: A panel study classifying deliveries according to Robson at a university hospital in Tanzania. BMC Preg Childbirth 2013;13:107. https://doi.org/10.1186/1471-2393-13-107

5. Mdegela MH, Muganyizi PS, Pembe AB, Simba DO, Van Roosmalen J. How rational are indications for emergency caesarean section in a tertiary hospital in Tanzania? Tanzan J Health Res 2012;14(4):236-242.

6. Litorp H, Kidanto HL, Rööst M, Abeid M, Nyström L, Essén B. Maternal near-miss and death and their association with caesarean section complications: A cross-sectional study at a university hospital and a regional hospital in Tanzania. BMC Preg Childbirth 2014;14:244. https://doi. org/10.1186/1471-2393-14-244

7. Eriksson J, Baker T, Jörnvall H, Irestedt L, Mulungu M, Larsson E. Quality of anaesthesia for caesarean sections: A cross-sectional study of a university hospital in a low-income country. Trop Med Int Health 2015;20(10):1329-1336. https://doi.org/10.1111/tmi.12553

8. World Health Organization. WHO Guidelines for the Management of Postpartum Haemorrhage and Retained Placenta. Geneva: WHO, 2009.

9. Kongnyuy EJ, Mlava G, van den Broek N. A criterion based audit of the management of obstructed labour in Malawi. Arch Gynecol Obstet 2009;279(5):649-654. https://doi.org/10.1007/s00404-008-0786-1

10. Sorensen BL, Elsass P, Nielsen BB, Massawe S, Nyakina J, Rasch V. Substandard emergency obstetric care - a confidential enquiry into maternal deaths at a regional hospital in Tanzania. Trop Med Int Health 2010;5(8):894-900. https://doi.org/10.1111/j.1365-3156.2010.02554.x

11. Maaløe N, Sorensen BL, Onesmo R, Secher NJ, Bygbjerg IC. Prolonged labour as indication for emergency caesarean section: A quality assurance analysis by criterion-based audit at two Tanzanian rural hospitals. BJOG 2012;119(5):605-613. https://doi.org/10.1111/j.1471-0528.2012.03284.x

12. van Beekhuizen HJ, Unkels R, Mmuni NS, Kaiser M. Complications of obstructed labour: Pressure necrosis of neonatal scalp and vesicovaginal fistula. Lancet 2006;368(9542):1210. https://doi. org/10.1016/S0140-6736(06)69477-4

13. Kabakyenga JK, Östergren P-O, Turyakira E, Mukasa PK, Pettersson KO. Individual and health facility factors and the risk for obstructed labour and its adverse outcomes in south-western Uganda.
. BMC Preg Childbirth 2011;11(11):73. https://doi.org/10.1186/1471-2393-11-73

14. Nilstun T, Habiba M, Lingman G, et al. Cesarean delivery on maternal request: Can the ethical problem be solved by the principlist approach? BMC Med Ethics 2008;9(1):11. https://doi org/10.1186/1472-6939-9-11

15. Signore C, Hemachandra A, Klebanoff M. Neonatal mortality and morbidity after elective cesarean delivery versus routine expectant management: A decision analysis. Semin Perinatol 2006;30(5):288-295. https://doi.org/10.1053/j.semperi.2006.07.010

16. Nama V, Wilcock F. Caesarean section on maternal request: Is justification necessary? Obstet Gynaecol 2011;13(4):263-269. https://doi.org/10.1576/toag.13.4.263.27693

17. Litorp H, Mgaya A, Kidanto HL, Johnsdotter S, Essén B. 'What about the mother?' Women's and caregivers' perspectives on caesarean birth in a low-resource setting with rising caesarean section rates. Midwifery 2015;31(7):713-720. https://doi.org/10.1016/..midw.2015.03.008

18. Selinger H. Maternal request for caesarean section: An ethical consideration. J Med Ethics 2016;40(12):857-860. https://doi.org/10.1136/medethics-2013-101558 


\section{RESEARCH}

19. Campbell OMR, Graham WJ, Lancet Maternal Survival Series steering group. Strategies for reducing matern mortality: Getting on with what works. Lancet 2006:368(9543):1284-1299. https://doi.org/10.1016/S0140-6736(06)69381-1

20. Okonkwo NS, Ojengbede OA, Morhason-Bello IO, Adedokun BO. Maternal demand for cesarean section: Perception and willingness to request by Nigerian antenatal clients. Int J Wom Health 2012;4:141-148. https://doi.org/10.2147/IJWH.S10325

21. Litorp H, Mgaya A, Mbekenga CK, Kidanto HL, Johnsdotter S, Essén B. Fear, blame an ransparency: Obstetric caregivers' rationales for high caesarean section rates in a low-resource setting. Soc Sci Med 2015;143:232-240. https://doi.org/10.1016/j.socscimed.2015.09.003

22. Bettes BA, Coleman VH, Zinberg S, et al. Cesarean delivery on maternal request: Obstetriciangynecologists' knowledge, perception, and practice patterns. Obstet Gynecol 2007:109(1):57-66. https://doi.org/10.1097/01.AOG.0000249608.11864.b6

23. Wiklund I, Edman G, Andolf E. Cesarean section on maternal request: Reasons for the request, selfestimated health, expectations, experience of birth and signs of depression among first-time mothe Acta Obstet Gynecol Scand 2007;86(4):451-456. https://doi.org/10.1080/00016340701217913

24. Størksen HT, Garthus-Niegel S, Vangen S, Eberhard-Gran M. The impact of previous birth experiences on maternal fear of childbirth. Acta Obstet Gynecol Scand 2013:92(3):318-324. https:// doi.org/10.1111/aogs.12072
25. Nieminen K, Stephansson O, Ryding EL. Women's fear of childbirth and preference for cesarean section - a cross-sectional study at various stages of pregnancy in Sweden. Acta Obstet Gynecol Scand 2009;88(7):807-813. https://doi.org/10.1080/00016340902998436

26. Kornelsen J, Hutton E, Munro S. Influences on decision making among primiparous women choosing elective caesarean section in the absence of medical indications: Findings from qualitative investigation. J Obstet Gynaecol Canada 2010;32(10):962-969. https://doi.org/10.1016 S1701-2163(16)34684-9

27. Hildingsson I, Nilsson C, Karlström A, Lundgren I. A longitudinal survey of childbirth-related fear and associated factors. I Obstet Gynecol Neonatal Nurs 2011;40(5):532-543, https:/doi. org $/ 10.1111 / j .1552-6909.2011 .01274 . x$

28. Cacciatore A, Giordano R, Romano M, La Rosa B, Fonti I. Putative protective effects of cesarean section on pelvic floor disorders. J Prenat Med 2010;4(1):1-4.

29. Shah A, Fawole B, M’Imunya JM, et al. Cesarean delivery outcomes from the WHO global survey on maternal and perinatal health in Africa. Int J Gynecol Obstet 2009;107(3):191-197. https://doi org/10.1016/j.ijgo.2009.08.013

30. Lumbiganon P, Laopaiboon M, Gülmezoglu AM, et al. Method of delivery and pregnancy outcomes in Asia: The WHO global survey on maternal and perinatal health 2007-08. Lancet 2010;375(9713):490-499. https://doi.org/10.1016/S0140-6736(09)61870-5 